\title{
Analysis of a petrol plume over England: 18-19 January 1997
}

\author{
F Welch, V S G Murray, A G Robins, R G Derwent, D B Ryall, M L Williams, A J Elliott
}

Chemical Incident Response Service, Medical Toxicology Unit, Guy's and St Thomas' Hospital Trust, London, UK F Welch

V S G Murray

School of Mechanical and Materials Engineering,

University of Surrey,

Guildford, UK

F Welch

A G Robins

The Meteorological Office, Bracknell, UK R G Derwent D B Ryall

Department of the Environment, Transport, and the Regions, London, UK M L Williams

School of Ocean

Sciences, University of Wales, Bangor, UK A J Elliott

Correspondence to: Miss Fiona Welch, Chemical Incident Response Service, Medical Toxicology Unit, Guy's and St Thomas' Hospital Trust, Avonley Road, London SE14 5ER, UK.

Accepted 10 June 1999

\begin{abstract}
Objectives-About 7000 tonnes of unleaded petrol were discharged into the English Channel after a tanker collision off Ostend on Saturday 18 January 1997. The petrol evaporated and the vapour plume was carried across the central part of England to Wales, resulting in reports of unidentified odours, and irritation of the eyes, skin, and upper respiratory tract. This work uses this incident to show how marine and atmospheric dispersion modelling together with routine air quality monitoring can assist in identifying hazards to the population at risk from chemical incidents.

Methods-Public health surveillance and results from environmental sampling were compared with the behaviour of the plume as predicted by computer modelling.

Results-The predicted plume path and dispersion were shown to correlate well with the results from surveillance and environmental analysis.

Conclusions-There is a need for public health professionals to interact with medical toxicologists, atmospheric and marine scientists and engineers, and other environmental experts in managing events of this nature.

(Occup Environ Med 1999;56:649-656)
\end{abstract}

Keywords: petrol spill; environmental monitoring; dispersion modelling

\section{Incident summary}

From 1232 hours on Sunday 19 January, the National Poisons Information Service (London) at the Medical Toxicology Unit (MTU), received 14 enquiries from across the country requesting information and advice relating to a strong petrol like smell. The enquiries came from accident and emergency departments, public health and environmental health offices, police, and the media. These enquiries concerned people experiencing irritation of the eyes, mucous membranes, and upper respiratory tract. The cause of these symptoms was not immediately clear. Some local sources suggested that local industry or aircraft jettisoning aviation fuel over the area could be responsible. However, the wide spread origin of the queries suggested another cause.

Discussions with accident and emergency departments, public health in Norfolk, Lincolnshire, Derbyshire, Nottinghamshire, Yorkshire, and Wirral, police stations in Notting- hamshire, Derbyshire, and Cheshire, coastguard operations room in Great Yarmouth and Dover, the Marine Pollution Control Unit, the Departments of Transport, Health and the Environment, and other National Poisons Information Services throughout the country led to the (as it then was) hypothesis that the cause was a collision in the English Channel on Saturday 18 January 1997. At 1500 hours on that day, the tanker, Bona Fulmar, collided in thick fog with the chemical carrying tanker, Teotal. The accident occurred 32 miles north west of Ostend in the French part of the Channel. Figure 1 shows the location of the incident.

It was reported that 7000 tonnes of unleaded petrol were spilt. ${ }^{1}$ Crew from the Marine Pollution Control Unit flew over the area on the morning of Sunday 19 January and reported that they could not see a slick. At the request of the Chemical Incident Response Service (CIRS), a water sample was taken from the spill site on the Sunday at about 1500 . This confirmed that unleaded petrol had been spilt.

With weather data for the period 18-19 January, the United Kingdom Meteorological Office used its long range pollution dispersion modelling system, NAME, ${ }^{2}$ to plot the likely course of the petrol vapour plume (fig 2 ). This indicated that the plume was first carried up the North Sea before the change in wind direction which resulted in it subsequently being swept across the central part of England to Wales.

The aim of the work described in this paper was to illustrate how marine and atmospheric dispersion modelling together with routine air quality monitoring can assist in identifying hazards to the population at risk from chemical incidents.

\section{Methods}

SURVEILLANCE

In this context, surveillance describes the monitoring of the population for possible end effects. The NAME predictions showed that in travelling up the North Sea and then over the

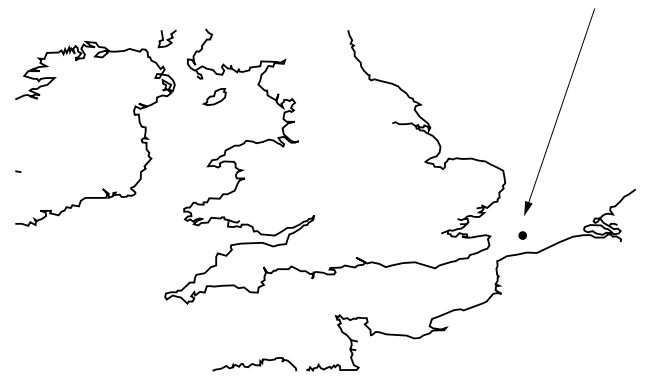

Figure 1 Map showing the site of the spill. 

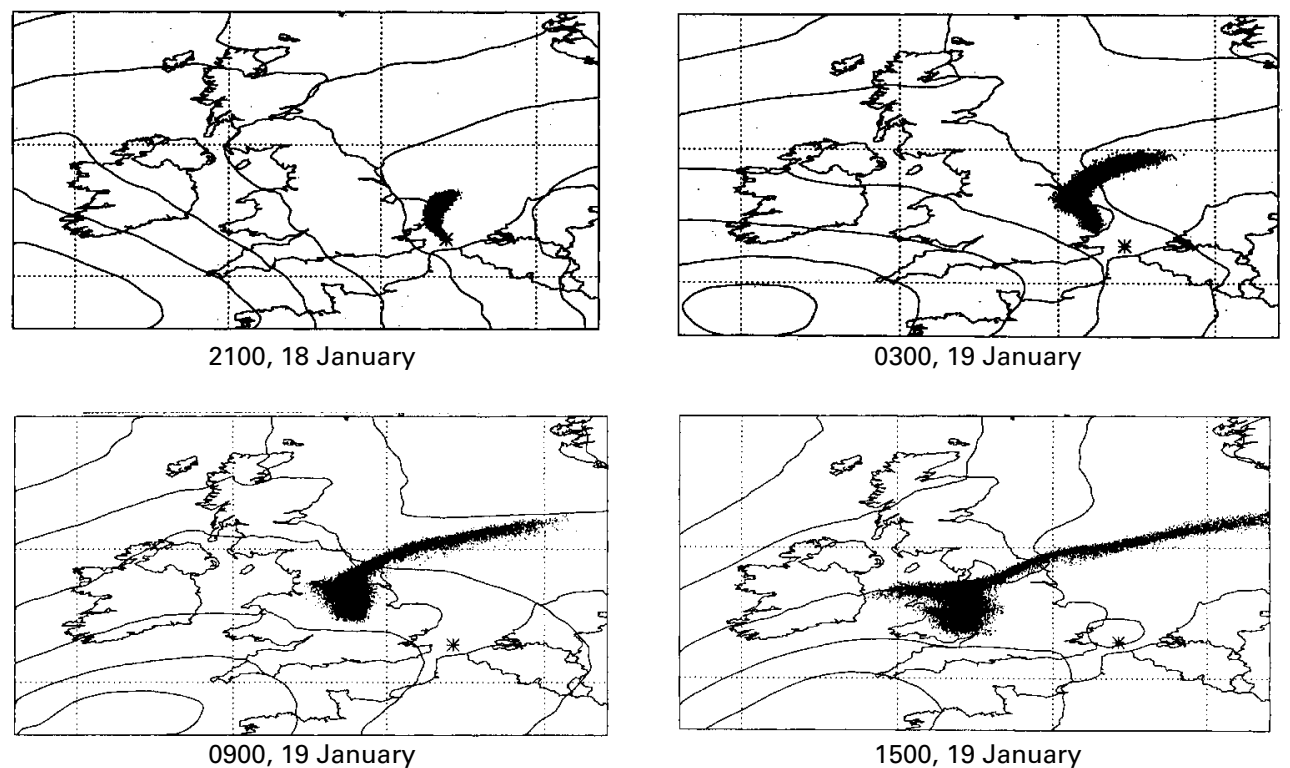

1500, 19 January
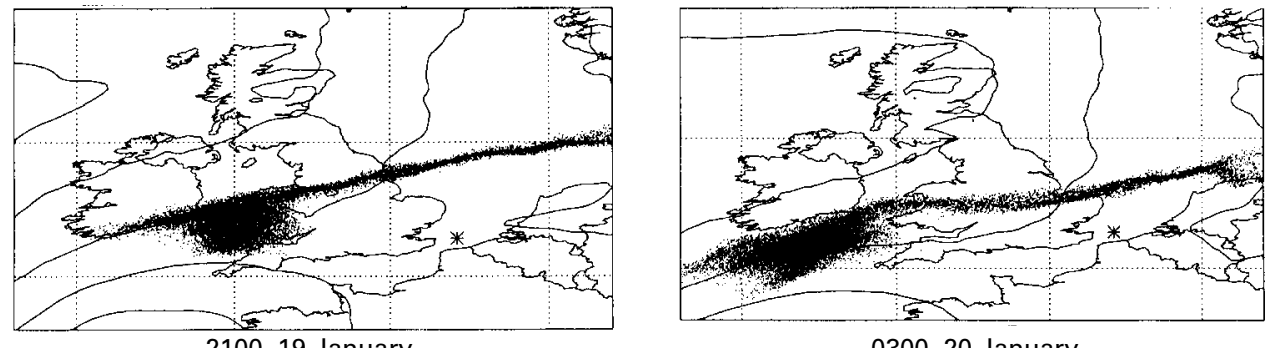

0300, 20 January
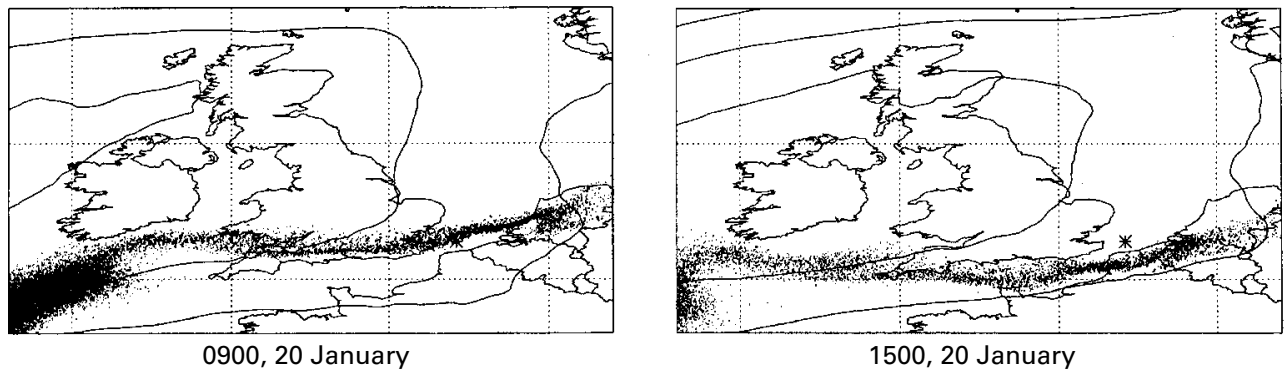

Figure 2 A sequence of NAME model output at 6 hour intervals for a steady release of 9 hours duration. Results from NAME output assuming a 9 hour release.

central part of England, the plume's first land fall was in Norfolk. Enquiries to the local consultant in communicable disease control subsequently established that no ill effects or odours had been reported there. Where available, chief emergency planning officer, police, and hospital admission logs were requested for review for areas possibly affected by the plume. Leeds, Liverpool, Birmingham, Cardiff, and Derbyshire were included as well as Norfolk. No accident and emergency departments reported cases to the National Poisons Information Service (London) or Chemical Incident Response Service over the seven day surveillance period, which lasted until Satruday 25 January.

ENVIRONMENTAL SAMPLING

Marine Pollution Control Unit

The Marine Pollution Control Unit (Maritime and Coastguard Agency) arranged for the collection of a sea water sample from the location of the spill on the Sunday afternoon at about
1500. The content of volatile hydrocarbons was determined by a "headspace analysis" of the vapour above the sample in a closed container. The analysis was carried out by the National Environmental Technology Centre at AEA Technology, Culham. Flame ionisation detector based gas chromatography (GC/FID) was used, this being the preferred method for analysis of such hydrocarbon mixtures. (Brian Jones, personal communication)

UK Hydrocarbon Monitoring Network

The UK Hydrocarbon Network (funded by the Department of Environment, Transport and the Regions) is a series of 13 continuous monitoring sites throughout the country where concentrations of hydrocarbons are measured. The network is run by the National Physical Laboratory. The analytical technique is again based on GC/FID methods, although the network procedures are automatic and operate on an hourly cycle. The concentrations of 26 
hydrocarbons are measured in an air sample collected over a 35 minute period in each cycle. The data are transmitted automatically to a central unit from where they are relayed to public information services such as CEEFAX, Teletext, and the web site of the DETR. Data displayed on these media and on a free telephone line are updated every hour.

Considerable fluctuations in the concentration of hydrocarbons at a fixed site are not unusual. These could be due to a local source - such as a petrol station, a factory, or motor vehicle exhausts. Many hydrocarbons, those identified in the headspace analysis included, are present both in petrol and vehicle exhaust fumes, so an increase in concentration could simply imply an increase in traffic or that the wind has passed through a polluted urban area. Hydrocarbon concentrations due to emissions in motor vehicle exhausts need to be subtracted to identify contributions from other sources. An ideal tracer for traffic emissions is a hydrocarbon which is present in the exhaust but not in the fuel: 1,3-butadiene is just such a compound, ${ }^{3}$ and changes in the concentrations of other hydrocarbons relative to 1,3-butadiene were used to identify contributions from sources other than traffic emissions.

Hydrocarbon concentrations from each site in question were taken from the United Kingdom air quality internet website. ${ }^{4}$ The concentration of each chemical, as identified by the head space analysis, was plotted against time. In most urban areas across the United Kingdom, the predominant source of most volatile organic compounds is traffic, so the next step in the analysis was to remove this component. The hourly mean concentrations were first normalised by division by their monthly mean. The normalised results showed the enhancement over average concentrations due to meteorological variations and changes in emission patterns or source behaviour. The normalised 1,3-butadiene concentrations were then subtracted from the results for all other pollutants to remove the contribution due to traffic exhaust emissions. Any excursions from zero in the resultant plot were therefore taken to indicate contributions from sources other than traffic exhaust.

Non-traffic related concentrations of 1,3butadiene may be due to several causes - such as local spills and industrial processes - which include the manufacture of synthetic rubber goods such as tyres. 1,3-Butadiene is formed during the combustion of petrol. ${ }^{5}$

Carbon monoxide has been used in the past as the indicator for traffic in analyses of this kind. This has some practical limitations in that most of the hydrocarbon monitoring sites are not at the same location as the associated carbon monoxide monitoring sites. The Birmingham East site however records carbon monoxide and hydrocarbons so in this case the monitoring results could be used to examine the relative performance of both means of identifying traffic emissions. An analysis based on carbon monoxide was found to yield almost identical results to the one based on 1,3- butadiene, lending confidence to the use of 1,3-butadiene.

DISPERSION MODELLING

Marine dispersion modelling

The period taken for the spill to evaporate was unknown and this introduced some uncertainty both in the prediction of its dispersion at sea and in the treatment of the resulting vapour plume in the atmosphere. In temperate conditions, components with a boiling point $<200^{\circ} \mathrm{C}$, such as petrol, tend to evaporate fully within the first day, with a half life (the time taken for $50 \%$ of the oil to disappear from the sea surface) of a few hours. ${ }^{6}$ No slick was visible when the Marine Pollution Control Unit flew over the location of the accident on the morning of 19 January, about 18 hours after the event.

The oil and chemical spill model, EUROSPILL, ${ }^{7}$ was used to simulate the motion of the oil slick on the sea surface. The spill simulations used surface winds provided by the Meteorological Office's operational numerical weather prediction models.

\section{Atmospheric dispersion modelling}

The main atmospheric dispersion modelling effort was undertaken with the Meteorological Office's NAME model. ${ }^{2}$ Like EUROSPILL, this too is a Lagrangian dispersion model driven by output from the Office's weather prediction models. Loss of plume material due to wet and dry deposition is included in the NAME model but was ignored in the present work.

The use of the three dimensional wind fields ensures that all relevant dispersion phenomena are included in the NAME calculations. Plume dispersion over short periods, typically an hour or so, can normally be approximated by spread and dilution about a straight trajectory. However, over longer periods the developing wind field generally causes the plume to deviate from its initial direction of travel and complex plume trajectories can result. Changes in wind direction with height cause plume elements at different altitudes to follow different trajectories and the resulting lateral spread can be more significant than the mixing due to turbulence. Vertical mixing then transfers the enhanced lateral spread to all levels.

Calculations were undertaken for different assumed evaporation periods from 3 to 24 hours, with a constant emission rate over the evaporation period. This treatment of the spill as a constant source strength for a fixed duration was clearly a great simplification. Comparisons of resulting predictions of concentrations with results of environmental monitoring were then used to estimate the most likely evaporation period.

Some simple dispersion calculations were also carried out with one of the long range transport models included in the R91 range of models. ${ }^{8}$ The likely ranges of hourly averaged concentrations at $500 \mathrm{~km}$ from the source were calculated for different spill evaporation times. 
Results of the headspace analysis

\begin{tabular}{ll}
\hline Hydrocarbon & $\begin{array}{l}\text { Concentration } \\
(p p b)\end{array}$ \\
\hline Benzene & 4.5 \\
Toluene & 2.0 \\
Ethylbenzene & 0.80 \\
$(m+p)$-Xylene & 0.88 \\
$o$-Xylene & 2.6 \\
Unidentified & $>1500$
\end{tabular}

Data supplied by Brian Jones, personal communication.

\section{Results}

SURVEILLANCE

A review of the chief emergency planning officer and police logs from the Derbyshire area

(Mary Newlands, personal communication) showed that reports of odours were logged from 0714 for over 2 hours on Sunday 19 January 1997. The reports ranged in description, with the odour source being described as chemicals, aviation fuel, glue, cellulose, or simply a funny sweet smell. At this stage there was no mention of the tanker accident on the previous day. The Chief Emergency Planning Officer contacted by telephone possible local sources such as chemical plants which were all able to confirm they were not the source. Review of the log from the Derby Royal Infirmary showed that there was no obvious increase in attendances for people with symptoms likely to be due to exposure to the passing
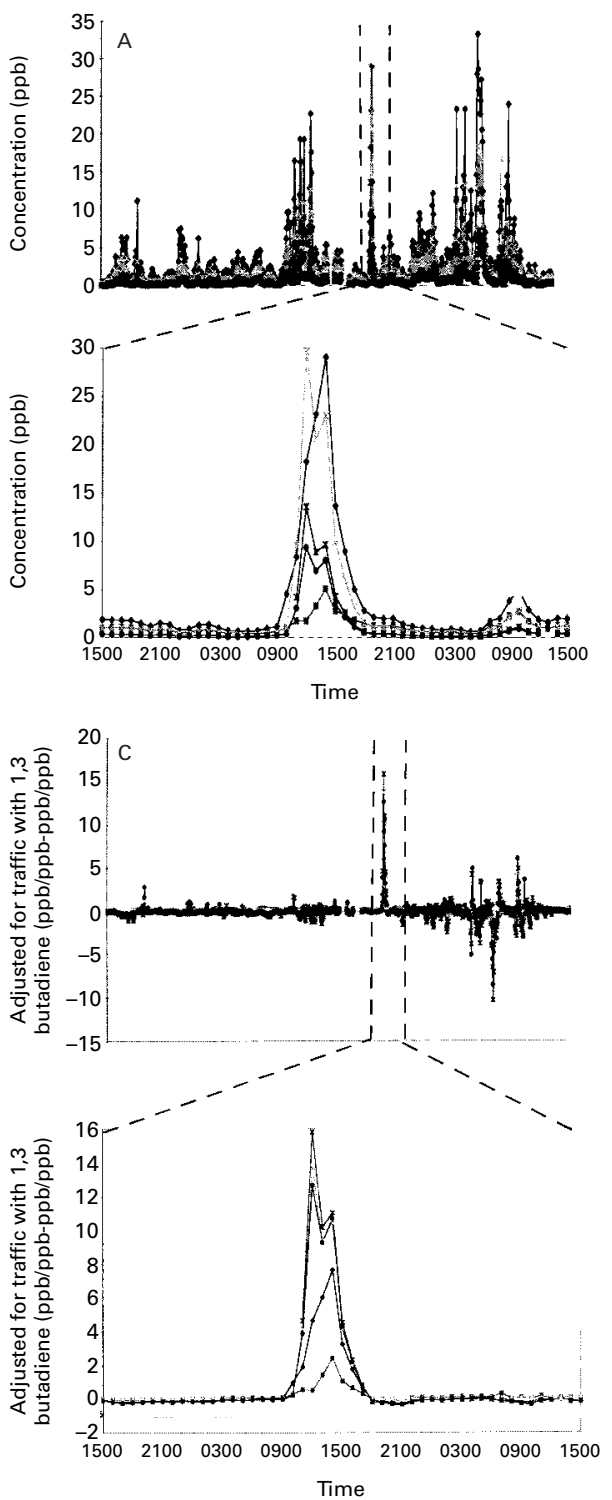

plume. Some police who were working during the incident reported sore throats, and streaming eyes and noses (Mary Newlands, personal communication).

Contact with other consultants in communicable disease control and poisons units in other areas showed that strange odours and symptoms were reported from Leeds, Chester, Liverpool, Birmingham, and Cardiff. Many of the reports came from Environmental Health Officers investigating the incident. There were no reports of odours or symptoms from Norfolk although the plume probably passed over this area between about 2100 GMT on 18 January and 0300 GMT on 19 January when it was still relatively concentrated.

\section{HEAD SPACE ANALYSIS}

Results of the head space analysis are summarised in the table. The FID output indicated
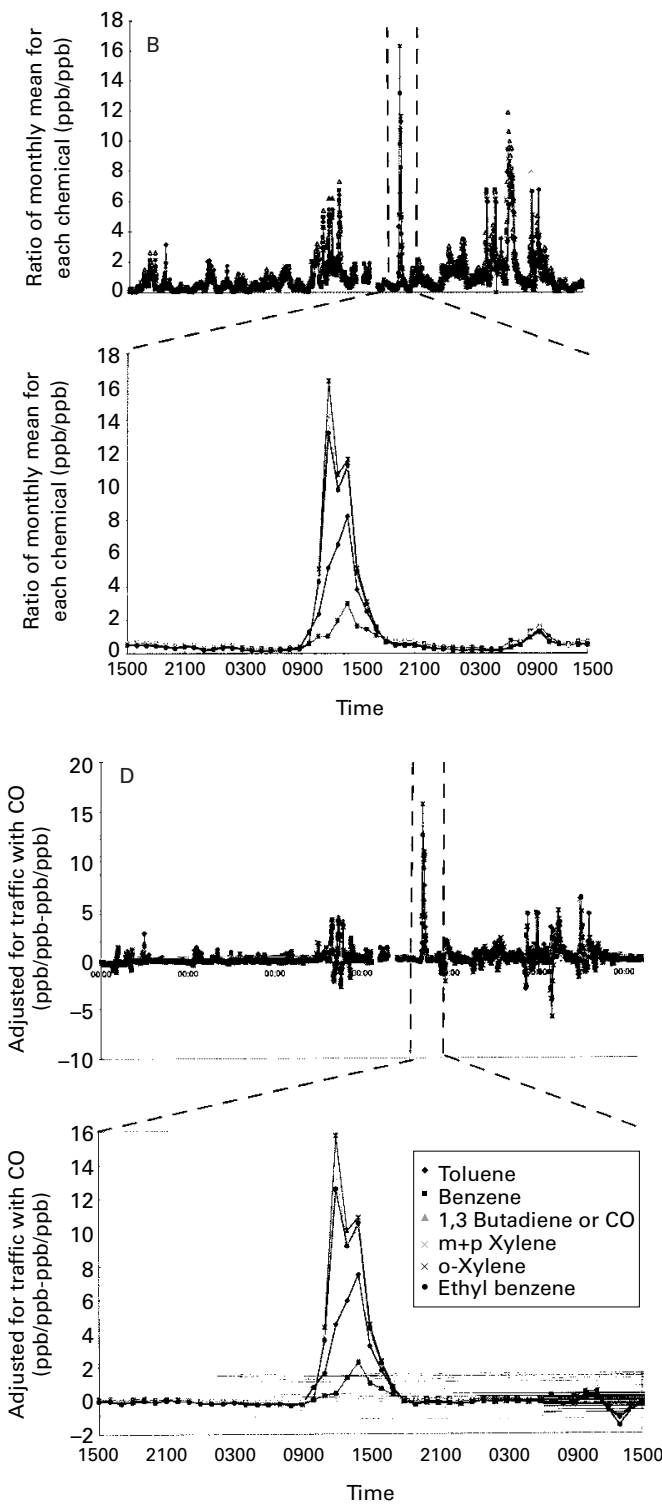

Figure 3 (A) Actual hydrocarbon concentrations at the Birmingham East monitoring site plotted as a function of time during the whole of fanuary and the period 17-20 fanuary. (B) Hydrocarbon concentrations normalised by their fanuary means at the Birmingham East monitoring site plotted as a function of time during the whole of the month and the period 17-20 Fanuary. (C) Normalised hydrocarbon concentrations with traffic components removed at the Birmingham East monitoring site plotted as a function of time during the whole of the month and the period 17-20 fanuary. (D) As (C) with carbon monoxide rather than 1,3 butadiene as the indicator. 


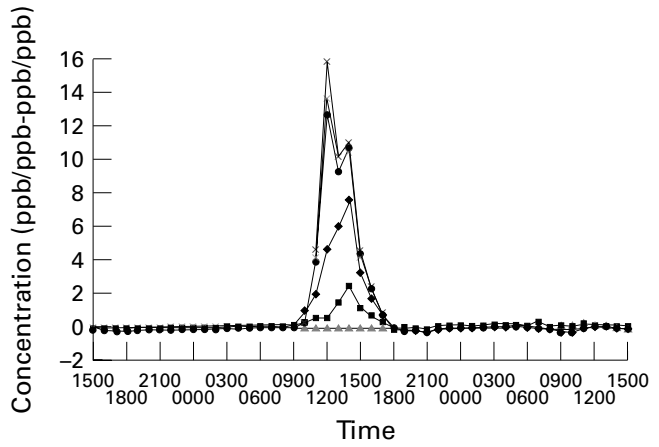

Birmingham
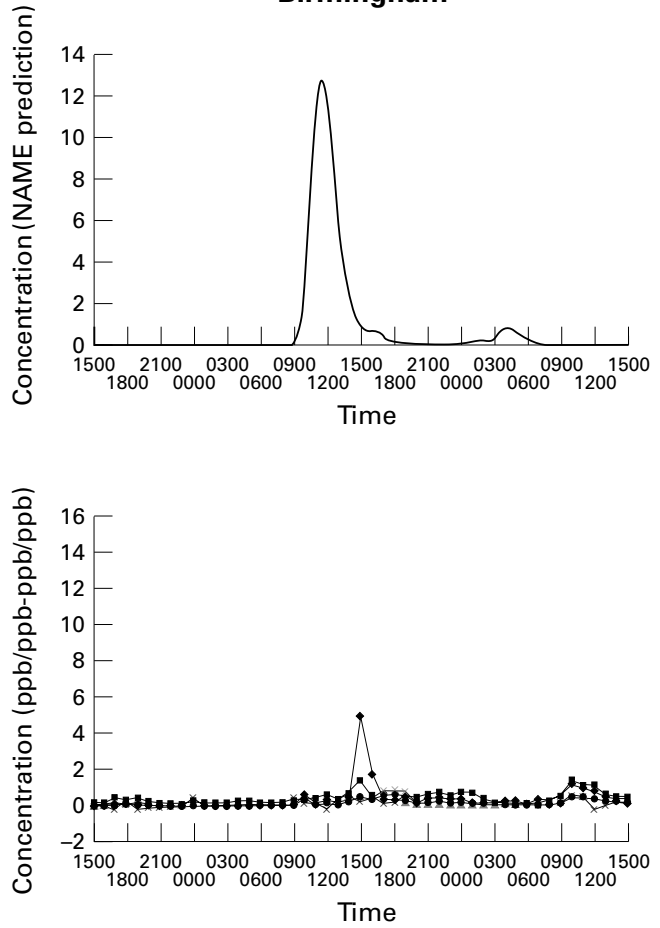

Liverpool

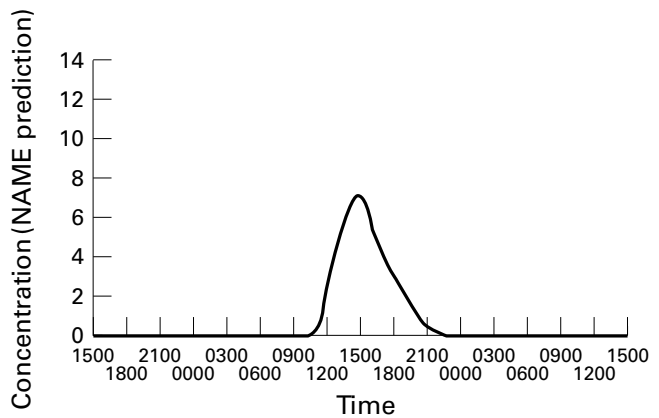

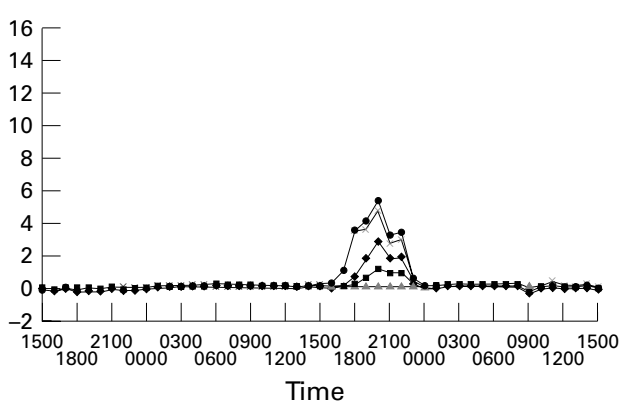

Cardiff
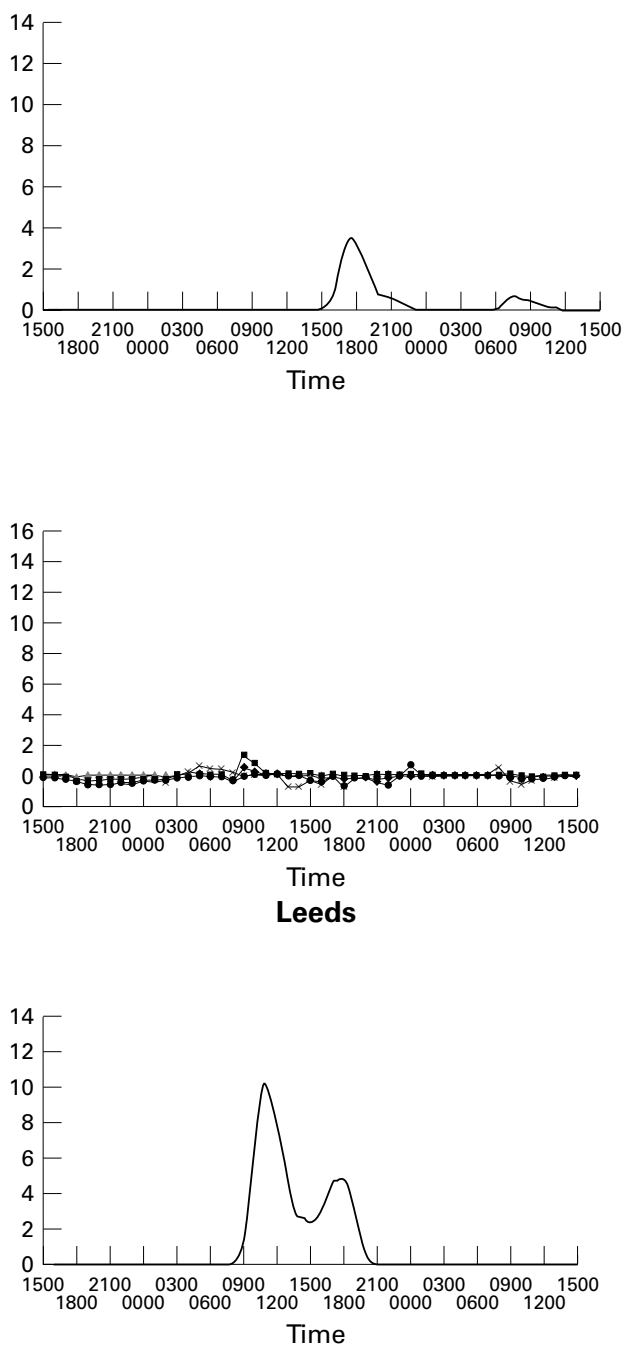

Figure 4 Predictions from the NAME model for plume concentrations as a function of time compared with normalised hydrocarbon concentrations with traffic components removed at the selected monitoring site plotted as a function of time during the period 17-20 fanuary.

that the unidentified compounds were probably C5 and C6 hydrocarbons. Separation and identification of these compounds was impossible as several unidentified peaks coeluted or partially coeluted in the part of the chromatogram where aliphatic C5 and C6 hydrocarbons usually elute. Some of the unidentified peak shapes suggested that they may be polar compounds, possibly oxygentated hydrocarbons. A ketone smell did seem to dominate the aroma of the sample although there may possibly have been esters present (Brian Jones, per- sonal communication). Ketones and esters are both oxygenated hydrocarbons.

HYDROCARBON NETWORK RESULTS

The output from most network sites showed some form of activity at the time of interest. However, a clearer picture emerged once the traffic generated component was removed by use of the techniques already described. Figure 3 illustrates the process for output from the Birmingham monitoring site. The actual hydrocarbon concentrations are plotted as a 
function of time during the whole of January and the period of interest in figure 3 A. Numerous peaks are apparent, including one of about 8 hours duration on the 19 January. The same results are also shown normalised by the appropriate monthly average. This shows that the peak concentrations of ethylbenzene, $m+p$ xylene and $o$-xylene on 19 January were about 15 times greater than their monthly averages (fig $3 \mathrm{~B}$ ). The traffic component was then removed by subtraction of the normalised 1,3 butadiene concentrations, leaving the results shown in figure $3 \mathrm{C}$. This reduced the baseline to zero throughout most of the month, with a clear peak in all the other hydrocarbons plotted. Similar results were obtained when carbon monoxide was used as the traffic indicator, althought the baseline becomes noisier (fig 3 D). Finally, analysis of the monitoring site output over a 12 month period subsequently confirmed that the peak concentrations found on 19 January were indeed exceptional (figs not included).

Figure 4 shows the normalised hydrocarbon levels with traffic components removed at the selected monitoring site plotted as a function of time 17-20 January at Birmingham East, Cardiff, Liverpool, and Leeds.

\section{DISPERSION MODELLING}

Marine dispersion

The displacement of the oil slick by wind and tide during the first day after the spill was calculated by the EUROSPILL model to be no more than a few $\mathrm{km} .{ }^{9}$ On the scale of the area affected by the gas cloud this was negligible.

Atmospheric dispersion

The output from the NAME model was a mapping of fluid particle number densities as a function of time after the start of the release. A sequence of results at 12 hour intervals is shown in figure 2 for a steady release of 9 hours duration. The predictions show that the plume first travelled in a northerly direction, making first landfall over Norfolk at around 2100 GMT on 18 January. The cloud of polluted air then became stretched out in a roughly east-west direction, although its centre drifted slowly to the north west. Material from the early part of the release remained over the North Sea but from about midnight polluted air from the North Sea part of the release began to cross central England, reaching Wales by about 1200 on 19 January. On the next day the whole plume, which by this time was very dilute, drifted slowly to the south.

An estimate of the likely duration of release was determined by comparing predicted concentrations for $3,6,9,12$, and 24 hour duration releases with observations at Birmingham, London, Cardiff, Bristol, and Liverpool.

A peak was predicted at Liverpool for all releases, implying that the material detected here was released soon after the accident (within 3 hours). Peaks at Birmingham and Cardiff were only predicted for releases of $\geqslant 9$ hours, while peaks at Bristol and London were predicted for releases of 12 and 24 hours respectively. As peaks were identified at Liverpool, Birmingham, and Cardiff, but not at London or Bristol, this suggests a release time of about 9 hours.

Assuming 140 tonnes of benzene was released over a 9 hour period, the model predicts maximum concentrations in the range $1-10 \mu \mathrm{g} / \mathrm{m}^{3}$ over the north of England, between 18 and 24 hours after the start of the release. This is consistent with concentrations of benzene found.

The results of simple dispersion modelling with the long range transport section of the R91 group of models ${ }^{8}$ give benzene concentrations in the range of $3-7.5 \mu \mathrm{g} / \mathrm{m}^{3}$ at a distance of $500 \mathrm{~km}$.

\section{Discussion}

SURVEILLANCE

Odours and associated effects were widely reported in the Midlands, although not in other regions where they were anticipated, such as Norfolk. Nevertheless, the geographical spread of reports suggests that a local source was not likely to be responsible. Several questions remain unanswered and are discussed later.

\section{ENVIRONMENTAL SAMPLING}

The headspace analysis showed that the sample consisted mainly of C5 and C6 hydrocarbons plus toluene, which is a C7 hydrocarbon, xylenes and ethylbenzene, both C8s. The headspace sample itself was not taken until Sunday 19 January, some time after the initial spill, and so the results cannot be considered as representative of the actual emissions at the time of the spill. Although the more volatile components had probably evaporated by this time, the results do confirm that the tanker contained a light petroleum fraction such as gasoline.

The odour which alerted most people was described as a sweet, solvent type smell and was probably due to oxygenated hydrocarbons. Ketones are sweet smelling and commonly used as solvents for lacquers, paint, and nail varnish removers..$^{10}{ }^{11}$ Esters too have a strong sweet odour, and are present in natural flavours and used in artificial flavourings. ${ }^{11}$

Figure 3 shows that the excess hydrocarbon concentrations in Birmingham persisted for about 8 hours and that during this period concentrations varied in a relatively smooth manner. This suggests a wide plume from a distant source for some duration. Signals from local spills or emissions would most likely be characterised by a short duration and highly fluctuating concentrations.

Birmingham has been used to illustrate the analysis procedure because this location gave the clearest signal of all the sites examined. The analysis clearly showed the hydrocarbon peak at the Cardiff monitoring site, and possibly also at Liverpool (fig 4) although at lower concentrations than at Birmingham. During the period of interest no $o$-xylene results were available at Cardiff, although the concentrations of the remaining compounds were in the same relative proportions as at Birmingham. 
Other sources of hydrocarbons, including 1,3 butadiene, near the Liverpool site (as well as traffic) might have affected both the monthly average and the concentrations found on 19 January, weakening any conclusions which might be drawn.

Analysis of the data from Belfast, Bristol, Edinburgh, London Eltham, UC London, Harwell, Leeds, Middlesborough, and Southampton failed to find unambiguous signs of the gas cloud.

The concentrations of other hydrocarbons monitored by the Network were examined for the Birmingham site. This showed the following hydrocarbons, all components of petrol, to be evident in the plume: $i$-butane, $n$-butane, trans but-2-ene, but-1-ene, cis but-2-ene, $i$-pentane, $n$-hexane, toluene, ethylbenzene, $m+p$-xylene and $o$-xylene.

The following were not detected: ethane, ethylene, propylene, propane, acetylene, $n$-pentane, 1,3-butadiene, trans pent-2-ene, cis pent-2-ene, 2-methylpentane, and $n$-heptane.

This confirmed that the increase in hydrocarbons was not traffic related as ethylene, propylene, acetylene, and 1,3-butadiene have all been identified as components of motor vehicle exhaust but not petrol. Toluene, ethylbenzene, $o$-xylene, $m+p$-xylene, $n$-butane, and $i$-butane have been clearly identified as present in both motor vehicle exhaust and petrol. However, their concentrations relative to benzene were considerably different from the values normally associated with urban air pollution, which again confirmed that the plume was not traffic related.

There is no obvious component of petrol that could have created a distinct odour at the levels of dilution indicated by dispersion modelling or implied by the measurements. Strictly speaking we cannot confirm that the odours were a result of the petrol spill. Although the possibility of chemical changes within the plume cannot be ruled out, we note that the accident occurred in winter and photochemical oxidation even over the long travel times involved is unlikely to have been efficient. Furthermore, summertime photochemical oxidation is not usually considered as a source of odorous organic compounds from evaporated petrol.

The hydrocarbon monitoring sites do not measure concentrations of oxygenated compounds. The analytical method, VOCAIR, requires the air to be dried by the use of a plastic membrane before analysis. This means that polar compounds (which include ketones, esters, and other odorous substances) are removed.

DISPERSION MODELLING

Concentrations of benzene predicted by the NAME and R91 models were of similar magnitude to those detected in the plume by the monitoring network. The odour threshold for benzene is $15 \mathrm{mg} / \mathrm{m}^{3},{ }^{12}$ typically a factor of $10^{3}$ larger than the predicted concentrations. Although individual people are able to detect odours well below this threshold, ${ }^{12}$ these results suggest that the plume was too dilute for ben- zene odours to be detectable. This conclusion probably applies to all primary emissions from the spill. The odour thresholds of some oxygenated compounds are much lower but their production in sufficient quantities would need to be explained, as does the cause of the other symptoms reported.

The output from the NAME model for a 9 hour emission, located plume material in space and time which matched the anecdotal and surveillance evidence. Moreover, the results showed that material from the later part of such an emission was carried across the midlands, something which did not arise with an emission of shorter duration. Figure 4 compares predictions for a 9 hour emission with monitoring site data. This shows close agreement on plume arrival and persistence times, and the variation of concentration with time, at the two sites where unambiguous plume signals were detected, Birmingham and Cardiff. This is also true of Liverpool, but not Bristol, despite its geographical proximity to Cardiff.

The NAME model suggests that Leeds was affected, but the monitoring suggests that this was not the case. Leeds was at the northern limit of the simulated plume's reach.

The deduction of an emission duration of about 9 hours is perhaps surprising in view of the volatility of petrol, but it provides a match between the predicted behaviour of the plume and the monitoring observations.

\section{Conclusions}

The reports and anecdotal evidence, together with the atmospheric modelling and measurement evidence suggests that the odours and reported symptoms experienced across Trent, Merseyside, the midlands, and south Wales were likely to have been due to the spill of petrol from the Bona Fulmar. This means that significant effects were detected at distances of the order of $\geqslant 500 \mathrm{~km}$ from the scene of the accident. In this case there were no serious adverse health effects, but had the meteorology been slightly different, taking the plume directly across south east England, or had the tanker contained chemicals which had similar physical properties, but substantially more serious toxicological effects, then the consequences could have been quite different. Although this was an unusual incident, it is not unique and the possibility of similar events cannot be discounted. The International Tanker Owners' Pollution Federation web site ${ }^{6}$ lists further details on oil spills.

At the time, no regard was given to those who may have been affected at large distances from the spill. Marine and meteorological modelling, together with environmental surveillance and monitoring, have been shown to be powerful tools for analysis of the event. These are clearly also suitable management tools, both in terms of short and long range impacts. Collaboration between the professions and organisations involved should be encouraged to provide an efficient overall approach. 
Several aspects of the incident have yet to be explained. The substances actually responsible for the odours and other symptoms have not been established. The plume dilution was too great for primary emissions to have been responsible.

It was found that 1,3-butadiene is an effective tracer for traffic pollution when used in conjunction with the technique described.

Many have contributed to the unravelling of this incident. In particular we would like to thank Brian Jones, AEA Technology; Peter Woods, National Physical Laboratory; Mary Newlands, consultant in communicable disease control, South Derbyshire Health Authority; and Paula MacDonald, consultant in communicable disease control, Communicable Disease Unit, Public Health Laboratories, Chester. The views expressed by MLW are his own and do not represent those of the Departm MLW are his own and do not represent those of the Department of the Environment, Transport, and the Regions. RGD and DR acknowledge the Public Meteorological Service research and development programme of the Meteorological Office for their funding and support. Financial support to FW from the Engineering Physical Science Research Council as part of the EngD in Environmental Technology at the University of Surrey is gratefully acknowledged.
1 Anon. Weather key factor in North Sea collision and gasoline spill. Oil Spill Intelligence Report 23 January 1997;2. 2 Maryon RH. Modelling the long range transport ofradionuclides following a nuclear accident. Nucl Energy 1994;33: 119-28.

3 Ye Y, Galbally IE, Weeks IA, et al. Evaporative emissions of 1,3-butadiene from petrol-fuelled motor vehicles. Atmospheric Environment 1998;32:2685-92.

4 Department of the Environment, Transport, and the Regions. Air quality information for the UK, 1998. http:/ www.aeat.co.uk/netcen/aqarchive/auto.html

5 Department of the Environment, Scottish Office, Welsh Office. The United Kingdom national air quality strategy, March 1997. London: The Stationery Office, 1997. (CM 3587.)

6 International Tanker Owners Pollution Federation. Oil spills from tankers. http://www.itopf.com/

7 Elliott AJ, EUROSPILL: oceanographic processes and NW European shelf databases. Marine Pollution Bulletins 1991; 11:548-53.

8 Jones JA. A model for long range atmospheric dispersion of radionuclides released over a short period. Harwell: National radionuclides released over a short period. Harwell: National

9 Elliott AJ. Simulations of atmospheric dispersion following a Elliott AJ. Simulations of atmospheric dispersion following a
spillage of petroluem at sea. Spill Science and Technology Bulletin 1999;5:39-50.

0 Fessenden RJ, Fessenden JS, eds. Organic chemistry, 3rd ed. New York: Brooks/Cole, 1986.

1 Ebbing DD, ed. General Chemistry. Boston: Houghton Mifflin, 1990.

12 Valentin FHH, North AA, eds. Odour control: a concise guide. Stevenage, Herts: Department of Industry. Warren Spring Laboratory Report, 1980.

\section{Occupational and Environmental Medicine - http://www.occenvmed.com}

Visitors to the world wide web can now access Occupational and Environmental Medicine either through the BMJ Publishing Group's home page (http://www.bmjpg.com) or directly by using its individual URL (http://www.occenvmed.com). There they will find the following:

- Current contents list for the journal

- Contents lists of previous issues

- Members of the editorial board

- Subscribers' information

- Instructions for authors

- Details of reprint services.

A hotlink gives access to:

- BMJ Publishing Group home page

- British Medical Association website

- Online books catalogue

- BMJ Publishing Group books.

The web site is at a preliminary stage and there are plans to develop it into a more sophisticated site. Suggestions from visitors about features they would like to see are welcomed. They can be left via the opening page of the BMJ Publishing Group site or, alternatively, via the journal page, through "about this site". 